\title{
The Using of "Guided Growth" for Correction of Coronal Deformities around the Knee in Skeletally Immature Children (Systematic review and Meta- analysis)
}

\author{
Yousef Ahdi Sawiris, Salah Abo-Seif and Ahmad Saeed Aly* \\ Orthopedic Surgery Unit, Ain Shams University’ 102 Marghany Street, Heliopolis, Cairo, Egypt
}

*Corresponding author: Ahmad Saeed Aly, Orthopedic Surgery Unit, Ain Shams University' 102 Marghany Street, Heliopolis, Cairo, Egypt, Tel: +202 01001228514; E-mail: ahmedsaidali2005@yahoo.com

Received date: October 10, 2018; Accepted date: October 17, 2018; Published date: October 29, 2018

Citation: Sawiris YA, Abo-Seif S, Aly AS (2018) The Using of "Guided Growth" for Correction of Coronal Deformities around the Knee in Skeletally Immature Children (Systematic review and Meta-analysis). Med Clin Rev Vol. 4 No. 3: 10.

Copyright: (C2018 Sawiris YA, et al. This is an open-access article distributed under the terms of the Creative Commons Attribution License, which permits unrestricted use, distribution, and reproduction in any medium, provided the original author and source are credited.

\section{Abstract}

Introduction: Angular deformities of the lower limbs are common during childhood. The concept of guided growth using a tension band plate is a breakthrough in the surgical correction of angular deformities. This approach has yielded satisfactory results and has low complication rates.

Patients and methods: We reviewed 210 papers with overall 433 patients and 809 deformities. Inclusion criteria included papers published from 2010 to 2017 in English literature. A Meta-analysis was done on 16 papers with seven outcomes: Change in mechanical axis deviation, Tibiofemoral angle, rate of excellent outcomes, implant breakage, implant migration, inadequate reduction and rebound phenomenon.

Results: Thirty two studies were included. Fifteen of them studied treatment of angular deformities by guided growth, three of them discussed the complications of using guided growth and five studies discussed Biomechanics of using guided growth. Sixteen studies were included in our cumulative meta-analysis.

Conclusion: Guided growth is effective in treating coronal deformities around the knee in skeletally immature children wither the cause was idiopathic or pathological. There is no limitation except if physeal bar is developed or the patient near maturity. Few complications are associated with guided growth techniques including rebound phenomenon, inadequate reduction, implant breakage and implant migration.

Keywords: Guided growth; Knee deformities; Eight plate; Staples; Growth modulation
Level of Evidence: 3 (systematic review of type 1, 2, 3 studies).

\section{Introduction}

Guiding growth by harnessing the ability of growing bone to undergo plastic deformation is one of the oldest orthopaedic principles. There has been renewed interest in surgical methods of physeal manipulation or 'guided growth'. Manipulating natural bone growth to correct a deformity is appealing, as it allows gradual correction by non- or minimally invasive methods $[1,2]$.

Heuter [1] first provided a scientific explanation for the phenomenon of mechanical manipulation of bone growth in 1862 , when he reported that increased pressure parallel to the axis of the epiphysis inhibits growth, while decreased pressure promotes it.

Seven years later, Volkmann [2] noted that changes in compressive forces cause asymmetrical growth of a joint. The 'chondral modelling' theory of Frost [3] suggests that the relationship between loading and chondral growth resembles an inverted $U$ shape. Physiological loading stimulates growth, while loads outside this range, either higher or lower, will inhibit it. Thus, minor degrees of joint incongruency, where the stresses remain within physiological limits, invoke a negative feedback in order to restore the joint to normal. Increasing incongruency results in the physis being subjected to loads outside the normal physiological range, invoking a positive feedback mechanism which results in progressive deformity.

This complex, non-linear relationship has many implications for the management of deformity, including a window outside which physeal manipulation may fail. Most importantly, it suggests that any intervention should be performed at an early stage when negative feedback correction can be harnessed. Early restoration of the mechanical axis is desirable to avoid permanent abnormality of the adjacent joint surfaces, which would otherwise lead to long-term morbidity. Performing a 
surgical physeal arrest using permanent or potentially reversible techniques may avoid the need for osteotomies in treatment of deformities in growing children [3].

The overall problem with performing a permanent physeal arrest is the need for timing of the procedure. The technique was first introduced by Phemister in 1933 [4] who described a technique to obtain permanent fusion of the growth plate by performing a rectangular resection of bone containing metaphysis, physis, and epiphysis with the resected area subsequently being reinserted with the ends reversed. By using this procedure, both equalizing of leg length and correction of frontal plane deformities such as genu valgum could be achieved according to Phemister [4]. (30)This procedure has disadvantages including considerable and prolonged postoperative care. One of the first attempts to perform a reversible hemiepiphysiodesis was made by Haas [5] who inserted a wire over the physis in growing dogs leading to growth arrest of the affected physis.

In 1949, Blount and Clarke reported on stapling of the epiphyseal plate as a method to correct both angular deformities and LLD [6-8]. Tension band plating developed to address some of the complications associated with the use of staples. It was first described by Stevens who developed the eight-plate implants (Orthofix; McKinney, TX, USA). These implants have been advocated to avoid compression of the growth plate and to reduce mechanical failures [9].

In this paper we systematically review the literature for the using of Guided Growth techniques to correct coronal deformities around the knee in skeletally immature children, covering the technical points, the outcomes and the occurrence of complications.

\section{Methods}

\section{Search strategy}

A review protocol was submitted and approved in PROSPERO. The literature was reviewed through electronic databases; Egyptian Knowledge Bank (EKB), Pub Med and Cochrane library about the using of guided growth for correction of coronal deformities around the knee in skeletally immature children.

We used the following keywords: Hemiepiphysiodesis, guided growth, eight plate, staples, coronal knee deformities, tension band plating, genu valgum, genu varum, growth plate and growth modulation for the search.

\section{Population, intervention, comparator, outcomes and study design}

We included studies done by randomized controlled trials (RCT) techniques, prospective studies and retrospective cohort studies with at least one data point before and after the intervention. Cross- sectional studies, expert opinion studies and case reports studies were excluded.
Skeletally immature children (at least 24 months of predicted growth were remaining) with coronal deformities around the knee (genu valgum or genu varum) either idiopathic or pathological physis were included. We excluded skeletally mature children, children with expected less than two years to reach maturity, physiological deformities and dynamic deformities due to ligamentous laxity as in neuromuscular disorders.

The literature search was limited to the English language with studies published from January 2010 till December 2017. The primary outcomes were changes in Mechanical Axis Deviation (MAD) and Tibiofemoral Angel (TFA). Secondary outcomes included excellent results rate, rate of implant breakage, implant migration, inadequate reduction and rebound phenomenon. This study has been reported according to the Preferred Reporting Items for Systematic Reviews and Meta-Analyses (PRISMA) guidelines [9].

\section{Study Selection}

A total of 210 studies were identified and imported into Mendeley Desktop V.1.17.13 Reference Manager. After removing duplicates/papers published before 2010, 63 articles underwent title screening. Studies were excluded if they were not human $(n=2)$, not a research study $(n=14)$, flexion knee deformities $(n=4)$, Ankle/Hip deformities $(n=8)$, Case reports $(n=9)$ and not in English $(n=3)$. Two independent reviewers assessed articles for eligibility; all disagreements were corrected through negotiated consensus with the third reviewer. A detailed PRISMA flow chart outlining the research steps is provided in (Figure 1).

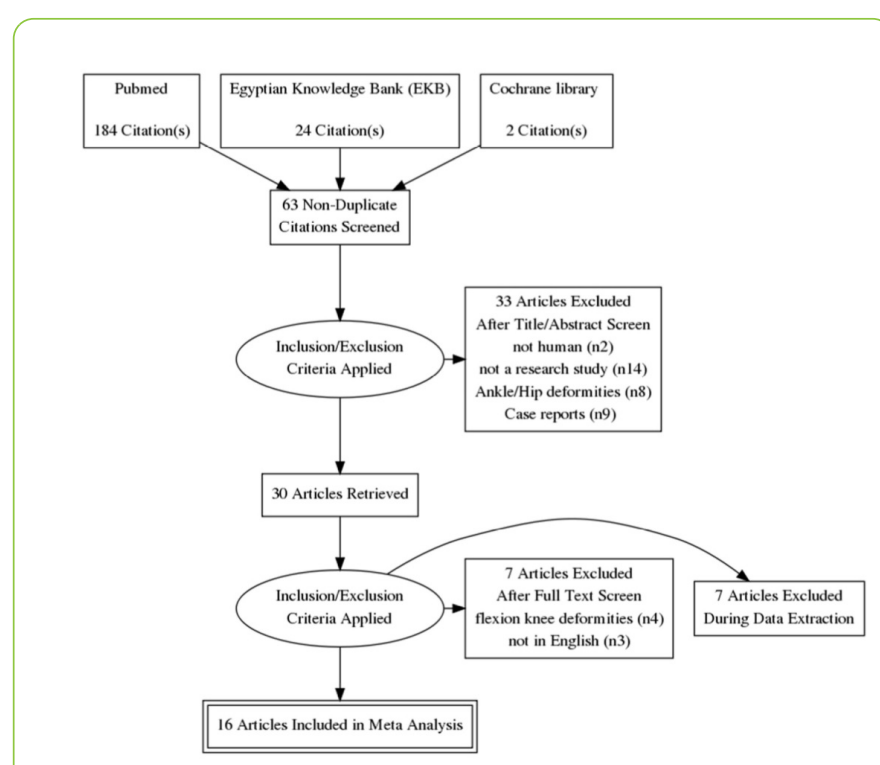

Figure 1 PRISMA Flow diagram summarizing the research steps $314 \times 273 \mathrm{~mm}$ (72 x $72 \mathrm{DPI})$.

\section{Data Extraction}

Relevant quantitative and qualitative data necessary for adequate study comparison and analysis was abstracted. 
Information on study objective, design, type of intervention, changes in Mechanical Axis Deviation (MAD) and Tibiofemoral Angel (TFA), excellent results rate, rate of implant breakage, implant migration, inadequate reduction and rebound phenomenon.

\section{Summary Measures and Statistical Analysis}

Statistical analysis was conducted using Comprehensive Meta-Analysis $^{\circledR}$ version 2.2.064 (BiostatTM, NJ, USA). Effect size for binary outcome measures was expressed as rate (fraction) with its $95 \%$ confidence limits $(95 \% \mathrm{Cl})$. For continuous outcome measures, effect size was expressed as standardized mean difference (SMD) and 95\% $\mathrm{Cl}$ of the SMD. Estimates from included studies were pooled using the Mantel-Haenszel fixed-effects method (FEM) if there was no significant heterogeneity among the studies. In presence of significant heterogeneity, the DerSimonian Laird randomeffects method (REM) was used. Heterogeneity was assessed using the Cochran $Q$ chi square test and I-squared $\left(I^{2}\right)$ index. $A$ funnel plot was calculated to assess publication bias. The Duval and Tweedie's [10] trim and fill method imputes the number and effect size of missing studies and recalculate the estimated effect size with the imputed studied included in the meta-analysis.

\section{Limitations}

Only two RCT were published, Most of the papers were single arm (not comparing guided growth with corrective osteotomy or staples with eight plate), Only one paper used Mechanical Axis Ratio for evaluation of outcomes, Presence of different modalities of evaluation of the primary outcomes (MAD, TFA, mLDFA, mMPTA etc), Sub grouping different from paper to another (pathological /idiopathic, genu varum/ valgum, Age, BMI) and Many outcomes with each needs Metaanalysis (7 outcomes).

\section{Results}

Twenty three studies were included in our systematic review. Fifteen of them studied treatment of angular deformities by guided growth, three of them discussed the complications of using guided growth and five studies discussed Biomechanics of using guided growth around the knee. Sixteen studies were included in our cumulative metaanalysis. The cumulative sample size of all studies was 433 patients with 809 deformities. Forest plots for the seven outcomes are illustrated in (Figures 2-8).

\section{Change in MAD}

\begin{tabular}{|c|c|c|c|c|c|c|c|c|c|}
\hline \multirow[t]{4}{*}{ Model } & \multirow{3}{*}{$\begin{array}{l}\text { Group by } \\
\text { DEFORMITY } \\
\text { G. valgum }\end{array}$} & \multicolumn{8}{|c|}{ Statistics for each study } \\
\hline & & \multicolumn{2}{|c|}{$\begin{array}{l}\text { Std diff } \\
\text { in means }\end{array}$} & \multirow{2}{*}{$\begin{array}{l}\begin{array}{c}\text { Standard } \\
\text { error }\end{array} \\
1.52\end{array}$} & \multirow{2}{*}{$\begin{array}{r}\text { Variance } \\
2.30\end{array}$} & \multirow{2}{*}{$\begin{array}{c}\text { Lower } \\
\text { limit } \\
-9.61\end{array}$} & \multirow{2}{*}{$\begin{array}{l}\text { Upper } \\
\text { limit } \\
-3.66\end{array}$} & \multirow{2}{*}{$\begin{array}{r}\text { Z-Value } \\
-4.37\end{array}$} & \multirow{2}{*}{$\begin{array}{r}\text { p-Value } \\
0.00\end{array}$} \\
\hline & & Baghel 2016 & -6.64 & & & & & & \\
\hline & G. valgum & Kulkarni 2015a & -2.39 & 0.54 & 0.30 & -3.46 & -1.32 & -4.39 & 0.00 \\
\hline Fixed & G. valgum & & -2.88 & 0.51 & 0.26 & -3.88 & -1.87 & -5.61 & 0.00 \\
\hline \multirow[t]{2}{*}{ Random } & G. valgum & & -4.28 & 2.11 & 4.46 & -8.42 & -0.14 & -2.03 & 0.04 \\
\hline & G. valgum/varum & Gyr 2013 & -0.99 & 0.26 & 0.07 & -1.50 & -0.48 & -3.80 & 0.00 \\
\hline Fixed & 6. valgum/varum & & -0.99 & 0.26 & 0.07 & -1.50 & -0.48 & -3.80 & 0.00 \\
\hline \multirow{2}{*}{ Random } & G. valgum/varum & & -0.99 & 0.26 & 0.07 & -1.50 & -0.48 & -3.80 & 0.00 \\
\hline & G. varum & Kulkarni 2015b & -3.58 & 0.82 & 0.67 & -5.19 & -1.97 & -4.36 & 0.00 \\
\hline Fixed & G. varum & & -3.58 & 0.82 & 0.67 & -5.19 & -1.97 & -4.36 & 0.00 \\
\hline Random & G. varum & & -3.58 & 0.82 & 0.67 & -5.19 & -1.97 & -4.36 & 0.00 \\
\hline Fixed & Overall & & -1.54 & 0.22 & 0.05 & -1.97 & -1.10 & -6.88 & 0.00 \\
\hline Random & Overall & & -1.27 & 0.25 & 0.06 & -1.75 & -0.78 & -5.14 & 0.00 \\
\hline
\end{tabular}

Figure 2 Forest plot for Change in MAD; 246 x 105 mm (220 x 220 DPI). 


\section{Change in TFA}

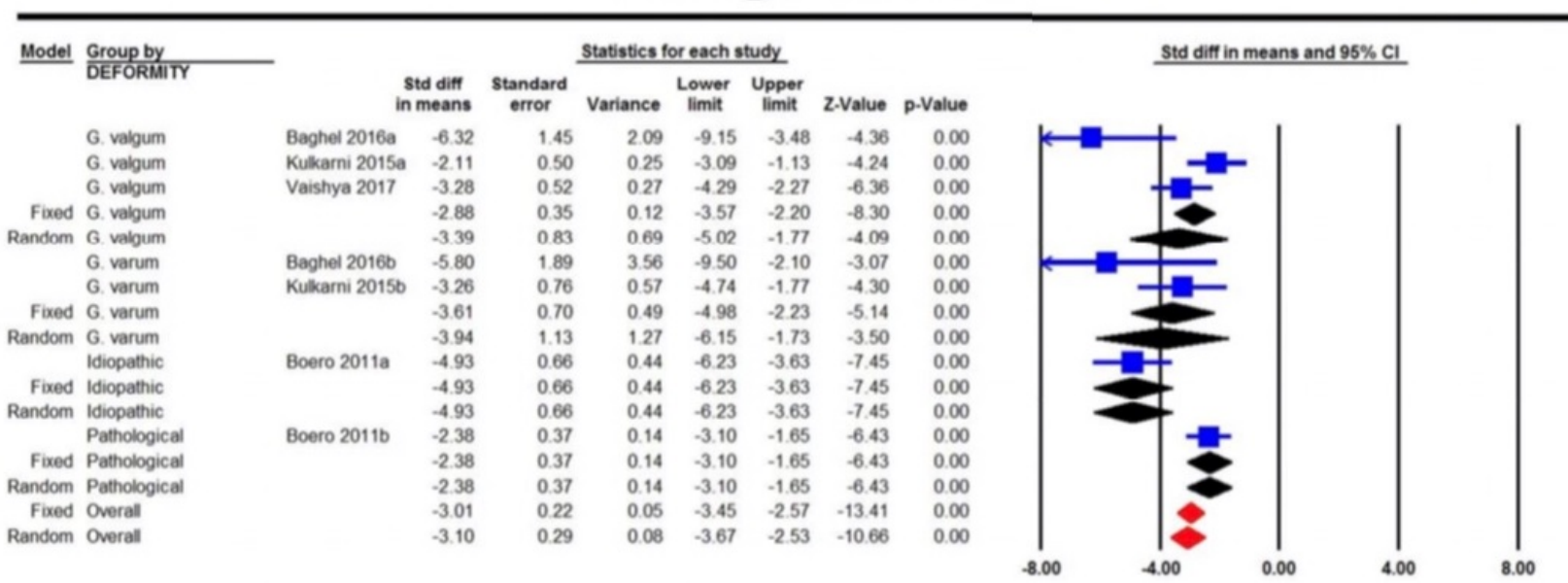

Figure 3 Forest plot for change in TFA $246 \times 120$ mm (220 x 220 DPI).

\section{Excellent Outcome}

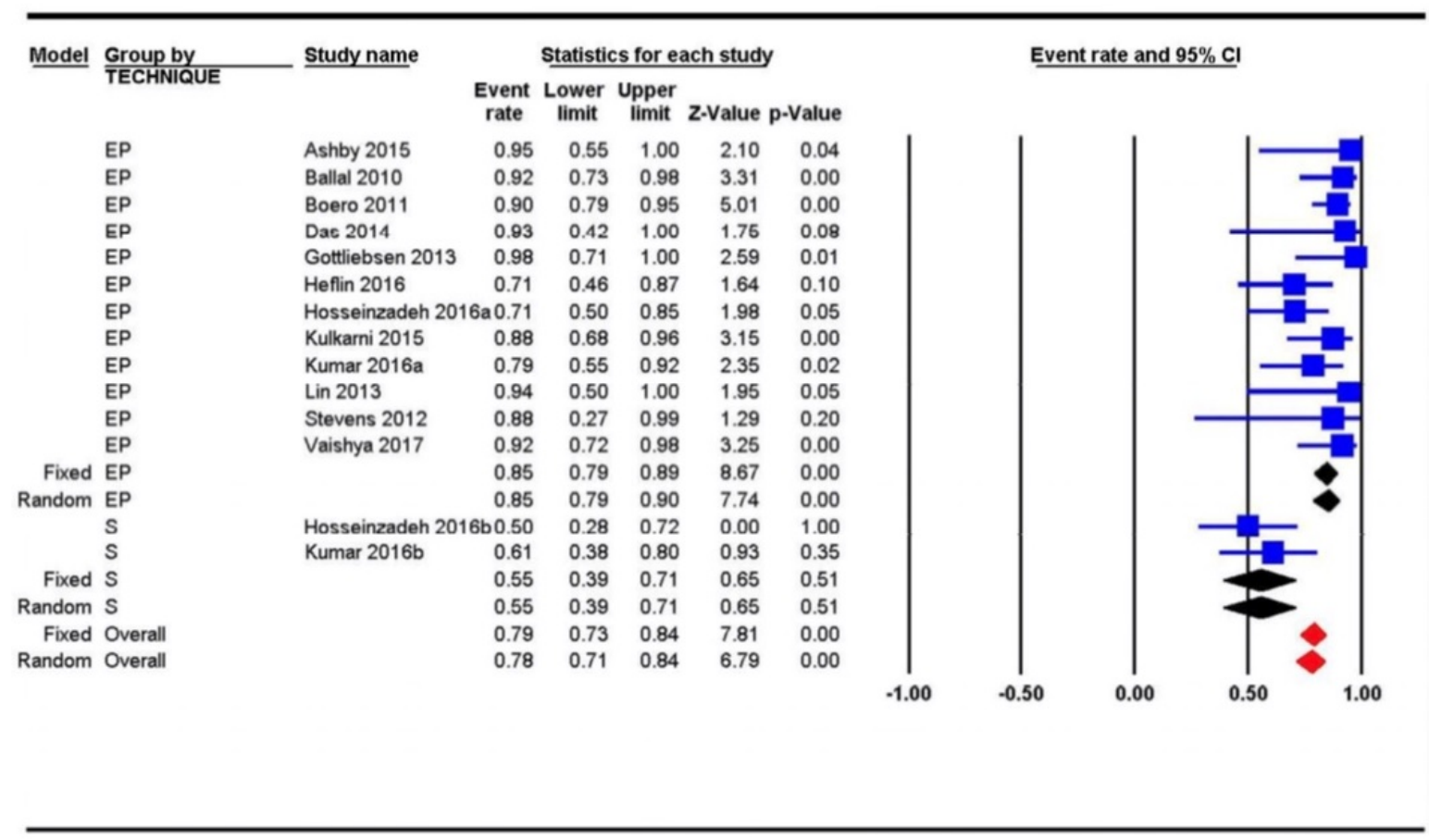

Figure 4 Forest plot for rate of excellent outcomes $251 \times 137 \mathrm{~mm}(220 \times 220 \mathrm{DPI})$. 


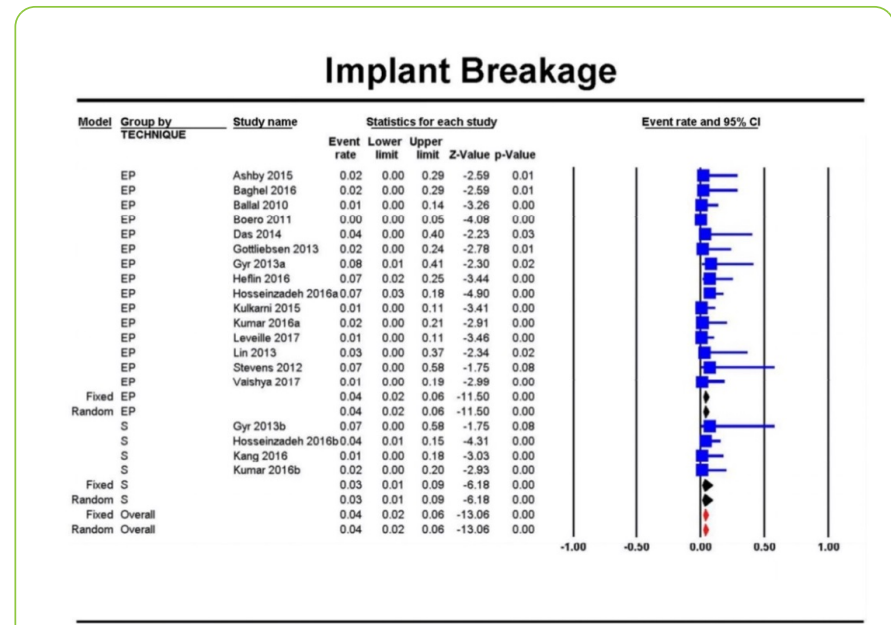

Figure 5 Forest plot for rate of implant breakage $196 \times 139$ $\mathrm{mm}(220 \times 220 \mathrm{DPI})$.

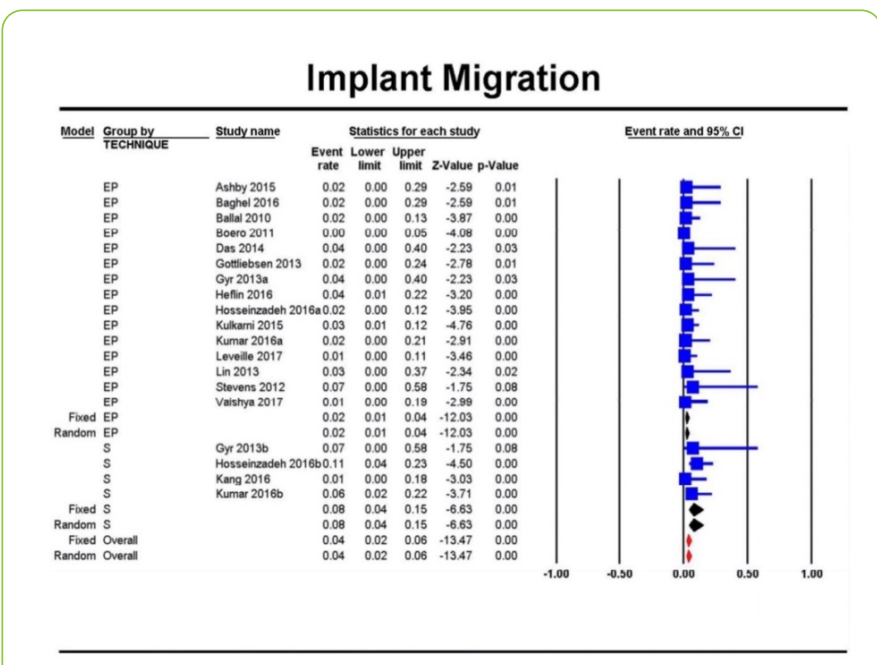

Figure 6 Forest plot for rate of impact migration $196 \times 139$ $\mathrm{mm}(220 \times 220 \mathrm{DPI})$.

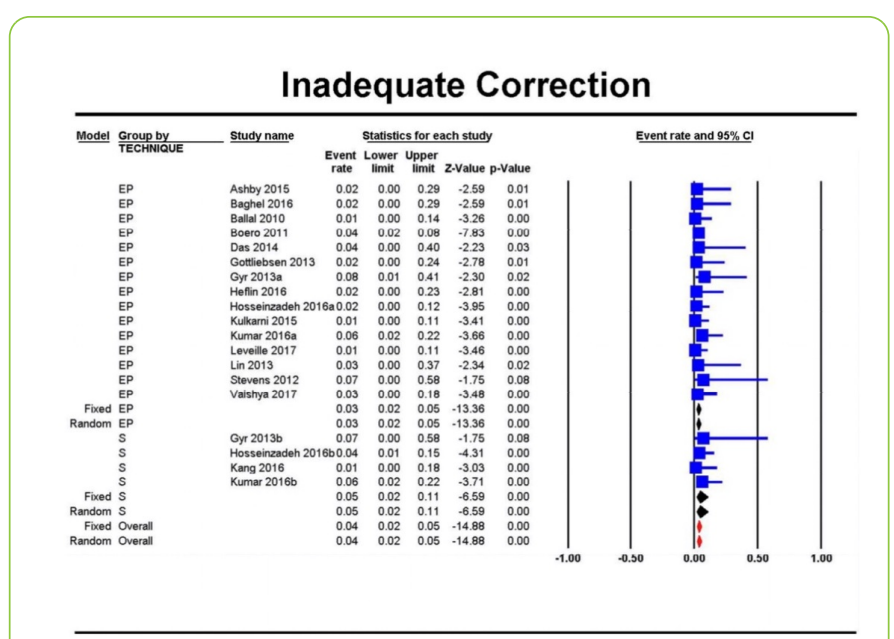

Figure 7 Forest plot for rate of inadequate correction $196 \mathrm{x}$ $139 \mathrm{~mm}(220 \times 220 \mathrm{DPI})$.

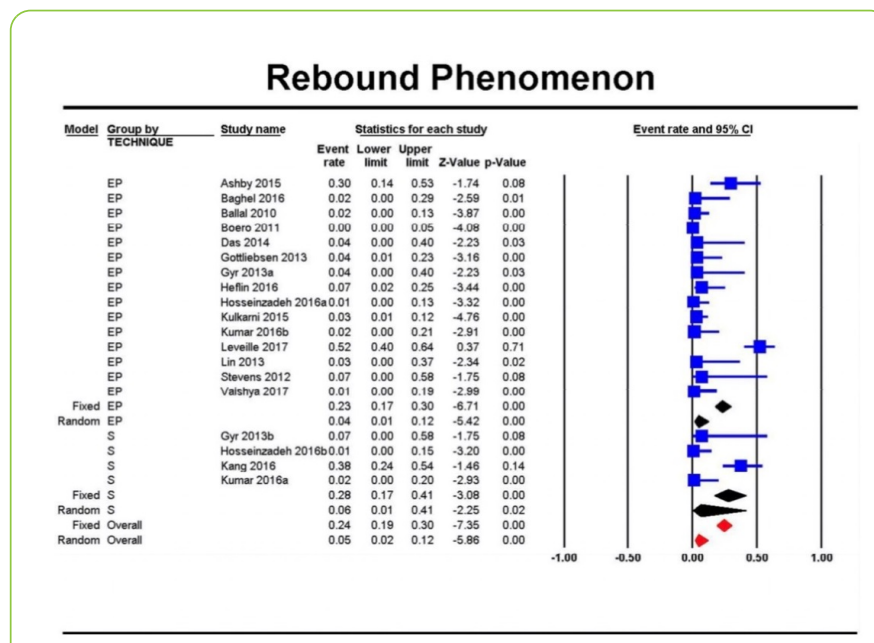

Figure 8 Forest plot for rate of rebound phenomenon $196 \mathrm{x}$ $139 \mathrm{~mm}(220 \times 220 \mathrm{DPI})$.

Tests of heterogeneity of the pooled results for the seven outcomes are illustrated in (Tables 1-7).

Table 1 Tests of heterogeneity for the change in the MAD.

\begin{tabular}{|c|c|c|c|}
\hline \multicolumn{4}{|c|}{ Heterogeneity Test } \\
\hline Q-value & df (Q) & P-value & I-squared \\
\hline 24.44 & 3.00 & $<0.01$ & 87.72 \\
\hline
\end{tabular}

Table 2 Tests of heterogeneity for the change in the TFA.

\begin{tabular}{|l|l|l|l|}
\hline \multicolumn{2}{|l|}{ Heterogeneity Test } & P-value & I-squared \\
\hline Q-value & df (Q) & $<0.01$ & 73.21 \\
\hline 22.40 & 6.00 & 21 \\
\hline
\end{tabular}


$Q$-value $=$ Cochran $Q$ statistic, $d f=$ degree of freedom (number of studies-1).

Table 3 Tests of heterogeneity for the rate of excellent outcome.

\begin{tabular}{|l|l|l|l|}
\hline \multicolumn{2}{|l|}{ Heterogeneity Test } & P-value & I-squared \\
\hline Q-value & 13.00 & 0.01 & 53.80 \\
\hline 28.14 & $\mathbf{Q})$ & \\
\hline Q-value=Cochran Q statistic, df=degree of freedom (number of studies-1). & \\
\hline
\end{tabular}

Table 4 Tests of heterogeneity for the rate of implant breakage.

\begin{tabular}{|l|l|l|l|}
\hline \multicolumn{2}{|l|}{ Heterogeneity Test } & df (Q) & P-value \\
\hline Q-value & 18.00 & 0.79 & I-squared \\
\hline 13.04 & 0.00 \\
\hline Q-value=Cochran Q statistic, df=degree of freedom (number of studies-1). \\
\hline
\end{tabular}

Table 5 Tests of heterogeneity for the rate of implant migration.

\begin{tabular}{l}
\begin{tabular}{l|l|l|l|}
\hline Heterogeneity Test & df (Q) & P-value & I-squared \\
\hline Q-value & 18.00 & 0.72 & 0.00 \\
\hline 14.10 & & \\
\hline
\end{tabular} Q-value=Cochran Q statistic, df=degree of freedom (number of studies-1). \\
\hline
\end{tabular}

Table 6 Tests of heterogeneity for the rate of inadequate correction.

\begin{tabular}{|l|l|l|l|}
\hline \multicolumn{2}{|l|}{ Heterogeneity Test } & df $(\mathbf{Q})$ & P-value \\
\hline Q-value & 18.00 & 0.98 & I-squared \\
\hline 7.72 & 0.00 \\
\hline Q-value=Cochran Q statistic, df=degree of freedom (number of studies-1). & \\
\hline
\end{tabular}

Table 7 Tests of heterogeneity for the rate of rebound phenomenon.

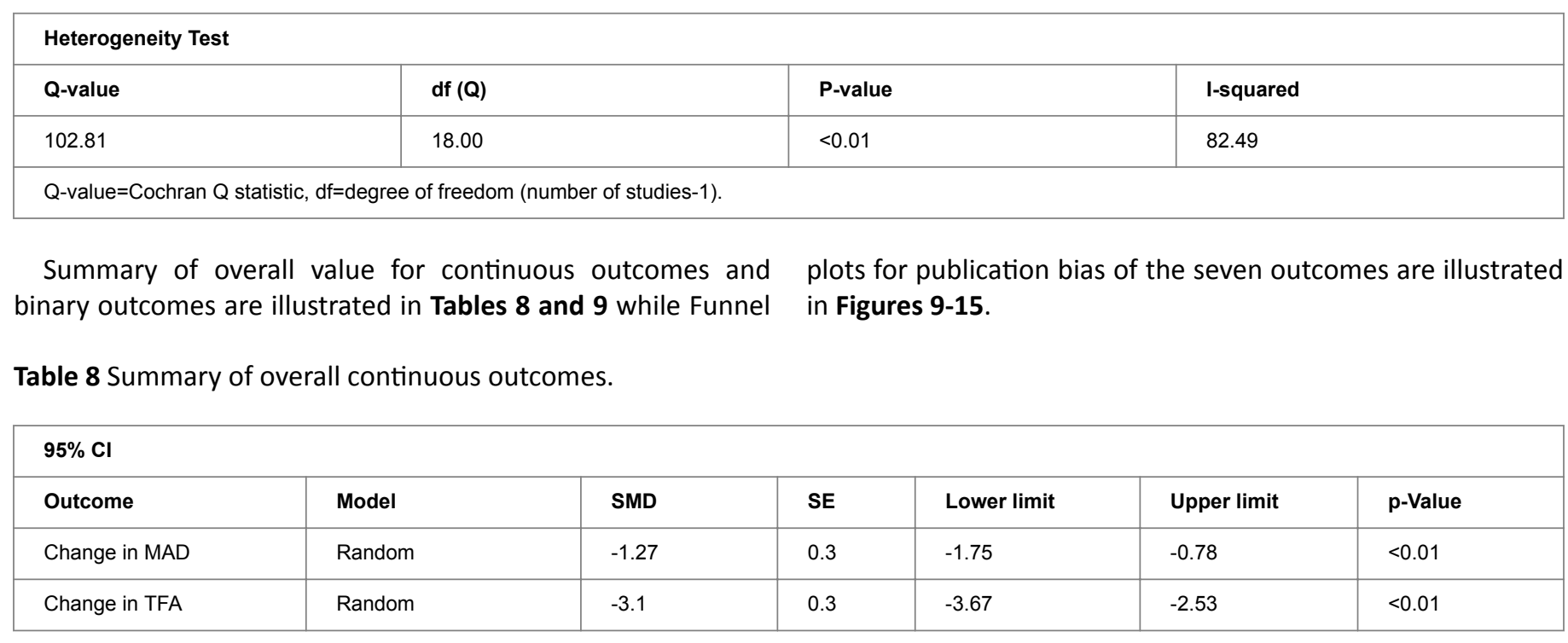


Continuous outcomes

$\mathrm{SMD}=$ standardised mean difference, $\mathrm{SE}=$ standard error.

Table 9 Summary of overall binary outcomes.

\begin{tabular}{|l|l|l|l|}
\hline $\mathbf{9 5} \% \mathrm{Cl}$ & Model & Event rate & Upper limit \\
\hline Outcome & Random & 0.78 & 0.7 \\
\hline Rate of excellent outcome & Fixed & 0.04 & 0 \\
\hline Rate of implant breakage & Fixed & 0.04 & 0 \\
\hline Rate of implant migration & Fixed & 0.04 & 0 \\
\hline Rate of inadequate correction & Random & 0.06 & 0.05 \\
\hline Rate of rebound phenomenon & & 0.12 & 0 \\
\hline Binary outcomes & &
\end{tabular}

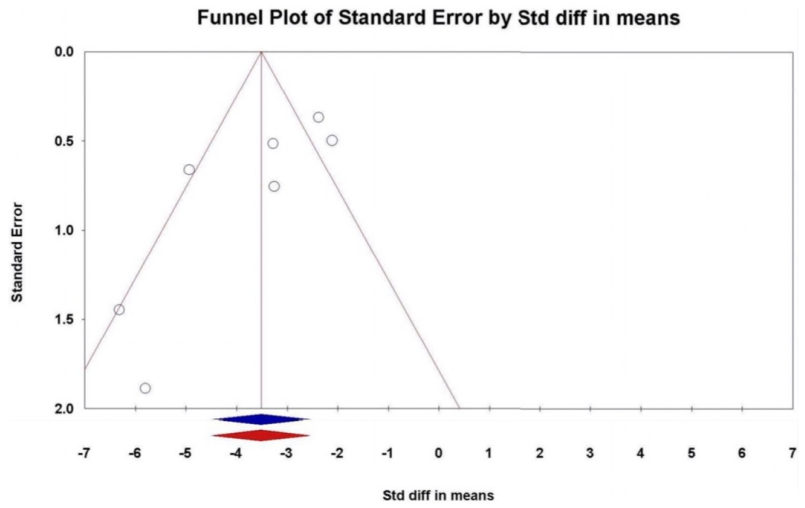

Figure 9 Funnel plots for change of MAD 215 x 134 mm (220 x 220 DPI).

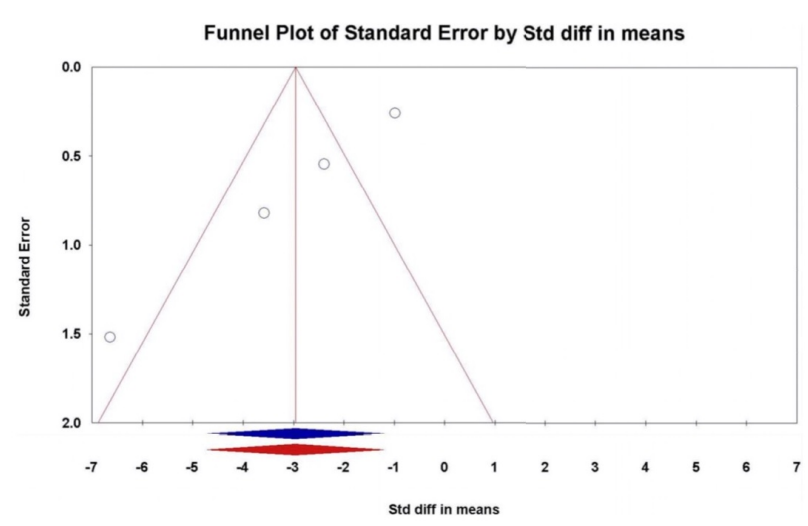

Figure 10 Funnel plot for change of TFA $215 \times 134$ mm (220 x 220 DPI).

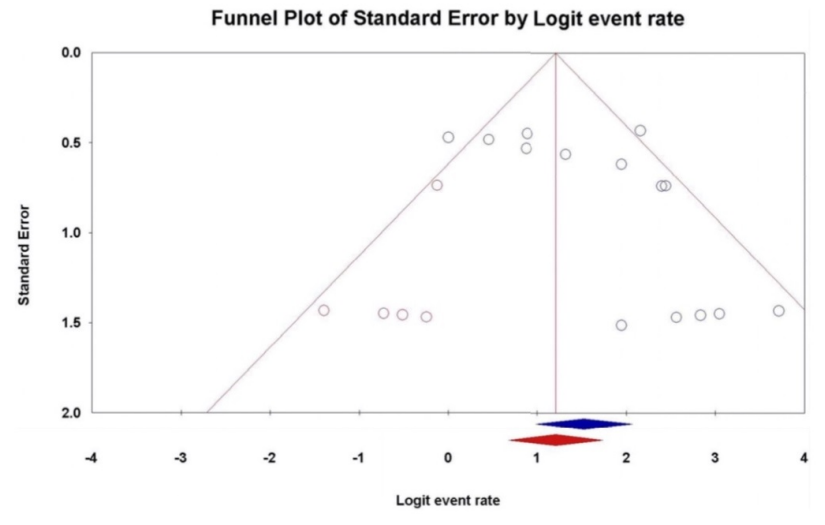

Figure 11 Funnel plot for Rate of excellent Outcomes $215 \mathrm{x}$ $136 \mathrm{~mm}(220 \times 220 \mathrm{DPI})$.

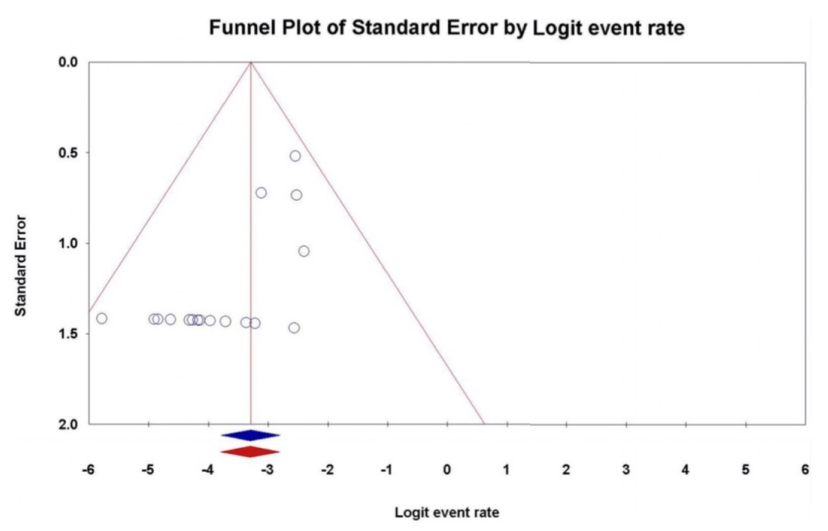

Figure 12 Funnel plot for Rate of Implant Breakage $215 \mathrm{x}$ $136 \mathrm{~mm}(220 \times 220 \mathrm{DPI})$. 


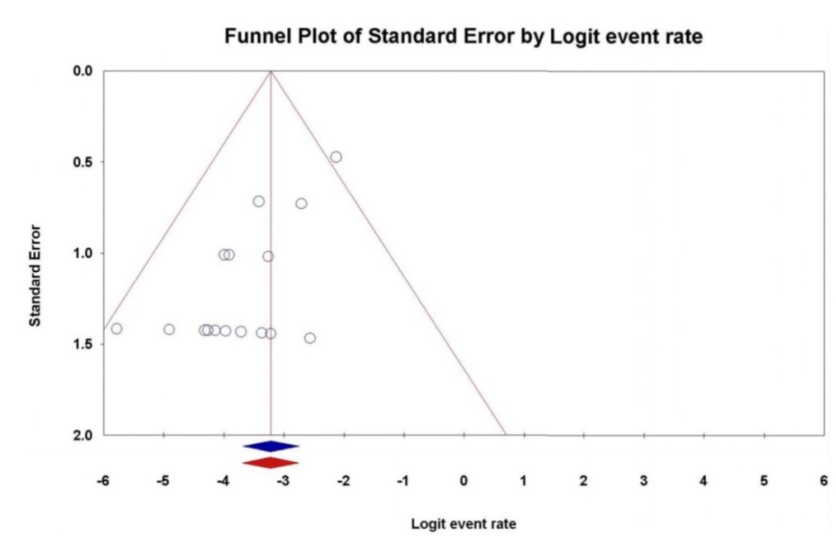

Figure 13 Funnel plot for Rate of Implant Migration $215 \mathrm{x}$ $136 \mathrm{~mm}(220 \times 220 \mathrm{DPI})$.

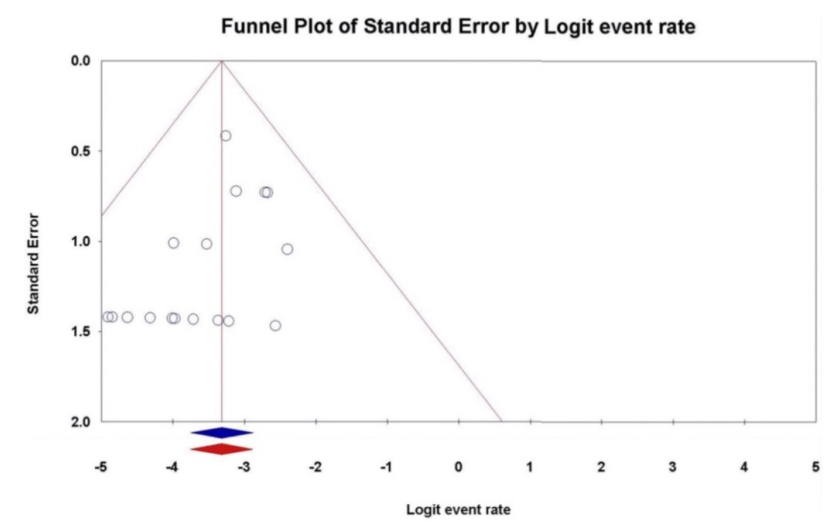

Figure 14 Funnel plot for rate of inadequate correction 215 x $136 \mathrm{~mm}(220 \times 220 \mathrm{DPI})$.

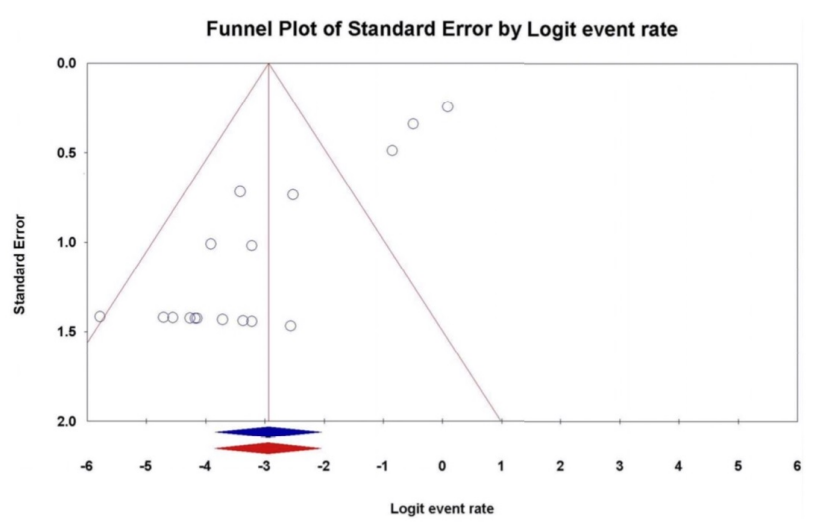

Figure 15 Funnel plot for rate of rebound phenomenon 215 x $136 \mathrm{~mm}$ ( $220 \times 220 \mathrm{DPI})$.

\section{Risk of Bias Assessment}

A risk of Publication bias assessment of all seven outcomes was measured using Funnel plot. There was publication bias regarding the excellent outcomes of Guided Growth techniques measured by I-squared $=53.4$ (Table 3 ) and by applying Duval and Tweedie's trim [10] and fill method, the corrected rate of excellent outcomes was $77 \%$ for all guided growth techniques instead of $82 \%$.

\section{Discussion}

In our Systematic review 433 patients with 809 deformities undergone different procedures for treatment of coronal angular deformities around the knee using the concept of guided growth by staples or titanium eight plates or stainless steel eight plates or stainless steel one third tubular plates. Guided growth techniques could be used in skeletally immature children provided that there is at least one year growth remaining and there is no physeal bar developed in the physis.

Eight plate was studied by Vaishya [11], Baghel [12], Heflin [13], Kulkarni [14], Ashby [15], Das [16], Stevens [9], Boero [17] and Ballal [18]. They found that it is effective in treating coronal angular deformities around the knee. Our MetaAnalysis showed that by using Eight Plate, MAD decreases by 4.28 Standardized mean difference (SMD) in Genu Valgum groups while in Genu varum groups, MAD decreases by 3.58 SMD.

The excellent outcomes rate by using Eight Plate were $85 \%$ while by using Staples were $55 \%$. There was a publication Bias regarding the excellent outcomes of Guided Growth techniques measured by I- squared $=53.4$ and by applying Duval and Tweedie's trim [10] and fill method, the corrected rate of excellent outcomes was $77 \%$ for all guided growth techniques. The rate of inadequate correction by eight plates was $3 \%$ while by Staples was $5 \%$.

Pathological physis was studied by Boero [17], Ashby [15] and Heflin [13]. They agreed that Idiopathic deformities get more benefit of guided growth than pathological one. Our meta-analysis showed that TFA corrected by 4.39 SMD in idiopathic groups while in pathological groups was corrected by $2.38 \mathrm{SMD}$. It's better to start earlier intervention by guided growth in pathological physis as the speed of correction is slow in comparison with the idiopathic group and also to prevent or even reverse secondary issues such as ligamentous laxity, lateral sublaxation and torsion or recurrence of deformity.

On the opposite side Colmenares-bonilla [19] recommends corrective osteotomy in treating patients with Morquio-A (MPS) because they usually had insufficient growth power especially when been diagnosed in adolescent age and this may help reduce arthritis progression in adjacent joints.

As we have different methods for the application of guided growth concept, Hosseinzadeh [20] and Kumar [21] studied the difference in the different constructs. Stainless steel constructs have higher rate of correction that explain its increased strength for angular correction. The stainless steel may increase the relative shear strength of that implant as they have not seen any hardware failures with the stainless 
steel Eight plate. Eight plates has higher rate of correction when compared to Staples.

On the opposite side, the study of Gottliebsen [22] reported that there is no difference in treating angular deformities with eight plate or Staples as regards to the results of correction of the deformities but this study was underpowered because of small number of population. Lin [23] proposed a different way for guided growth concept using two holes one third tubular plate and it showed excellent results in treating angular deformities around the knee. It could be used in developing countries where there are no eight plates available.

Post operatively Fillingham [24] recommends immediate postoperative physiotherapy as it prevents significantly the delay in return of function.

Our meta-analysis showed that Rebound Phenomenon rate was $4 \%$ in Eight Plate group and 6\% in Staples group.

Leveille [25], Kang [26] and Burghardt [27] modulation at a young age (below 10 years in girls, below 12 years in boys) and those with large initial deformities ( $>20$ degrees mechanical axis deviation from neutral). They also found that when we have a rate of correction $\geq 8.5^{\circ}$ year and a Body mass index $<21 \mathrm{~kg} / \mathrm{m}^{2}$, rebound phenomenon is highly recommend $5^{\circ}$ of overcorrection especially when we have growth anticipated. Mechanical Failure also occurs most probably in the metaphyseal screw not where the head meets the shank but where the shank enters the lateral cortex. Our meta-analysis showed that the rate of implant breakage was $4 \%$ in eight plate group while in staples group was $3 \%$.

Leveille [25], Kang [26] and Burghardt [27] bending of the plate and alternately tightening the 2 screws. It is advised that screws should not be placed widely divergent because it may impinge on the plate prematurely. They also recommend the using of solid screws rather than cannulated screws. Screw breakage was reported in patients with an average BMI of 37.8 $\mathrm{kg} / \mathrm{m}^{2}$ range $\left(19.2\right.$ to $\left.70.2 \mathrm{~kg} / \mathrm{m}^{2}\right)$. For them, it is recommended to use two parallel eight-Plates in either a parallel or oblique fashion. Staples have higher risk of migration/extrusion than the other constructs because of the fulcrum being extra periosteal. Our meta-analysis showed that the rate of implant migration was $2 \%$ in eight plate group and $8 \%$ in Staples group.

In distal medial femoral hemiepiphysiodesis, Bachmann [28] reported that there is a risk in injuring MPFL but not the $\mathrm{MCL}$ which explain the excessive postoperative pain that sometimes occur together with reduced ROM after temporary hemiepiphysiodesis at distal medial femur with a plate and two screws.

Gyr [29] studied treating angular deformities in paediatric amputees using the means of guided growth which was successful and avoided the complications of using external or internal fixation devices.

Marangoz [30] documented that there is correlation, between the delta joint orientation angle and the delta interscrew angle. This correlation is not related to the growth rate of the physis. It is a purely mathematical correlation, independent of the age and sex of the patient. It can be used to measure the anatomical changes of the joint line without the need of full length $X$-rays.

Ceroni [31] studied the modification of the alignment between the tibial tubercle (TT) and trochlear groove (TG) that occur during guided growth. They stated that for every degree of angular correction recommend that the plate should be coapted to the bone by pre during femoral distal hemiepiphysiodesis, there is a $1 \mathrm{~mm}$ simultaneous lateral or medial transfer of the TT. And during proximal tibial hemiepiphysiodesis, $8^{\circ}$ of angular correction will roughly translate the TT by $1 \mathrm{~mm}$.

Masquijo [32] studied the modified Paley technique. It seems that this technique reduces operative time, radiation exposure, and incision size for guided growth around the knee.

\section{Conclusion}

Guided growth is effective in treating coronal deformities around the knee in skeletally immature children wither the cause was idiopathic or pathological. There is no limitation except if physeal bar is developed or the patient near maturity. Few complications are associated with guided growth techniques including rebound phenomenon, inadequate reduction, implant breakage and implant migration.

\section{Compliance with Ethical Standards}

\section{Funding statement}

No benefits in any form have been received or will be received from a commercial party related directly or indirectly to the subject of this article.

\section{Ethical statement}

Ethical approval: This article does not contain any studies with human participants or animals performed by any of the authors.

\section{Informed consent}

Informed consent was not required. The study was registered with PROSPERO (registration number: CRD42017070157), and was approved by Research Ethics Committee (REC) of Faculty of Medicine, Ain Shams University.

\section{Conflict of Interest}

All the three authors declare that they have no conflict of interest.

\section{References}

Hueter C (1863) Anatomical studies on extremity joints newborn and adult. Arch Pathol Anatom Physiol Clin Med 26: 484-519. 
2. Volkmann $R$ (1869) The diseases of the locomotor organs Billroth Pitha, ed Man Gen Spec Surgery Stuttgart Ferdinand Enke 2: 694

3. Frost HM (1979) A chondral modeling theory. Calcifi Tissu Intern 28: 181-200.

4. Phemister DB (1933) Operative arrestment of longitudinal growth of bones in the treatment of Deformities. J Bone Jt Surg 15: $1-15$.

5. Haas SL (1945) Retardation of bone growth by a wire loop. J Bone Jt Surg Am 27: 25-36.

6. Moher D, Liberati A, Tetzlaff J, Altman DG, PRISMA Group (2009) Preferred reporting items for systematic reviews and metaanalyses: The PRISMA statement. BMJ 339: 2535.

7. Stevens PM, Novais EN (2012) Multilevel guided growth for hip and knee varus secondary to chondrodysplasia. J Pediatr Orthop 32: 626-630.

8. Blount WP, Clarke GR (1949) Control of bone growth by epiphyseal stapling: A preliminary report. J Bone Jt Surg Am 31: 464-478.

9. Stevens PM (2007) Guided growth for angular correction: A preliminary series using a tension band plate. J Pediatr Orthop 27: 253-259.

10. Duval S, Tweedie R (2000) Trim and fill: A simple funnel-plotbased method of testing and adjusting for publication bias in meta-analysis. Biometrics 56: 455-463.

11. Vaishya R, Shah M, Agarwal AK, Vijay V (2017) Growth modulation by hemi epiphysiodesis using eight- plate in Genu valgum in paediatric population. J Clin Orthop Trauma (Article in Press).

12. Baghel A, Agrawal A, Sinha S, Singh RP, Sharma V, et al. (2016) Evaluation of rate of correction of angular deformity of knee using tension band plate. Intern J Contemp Med Res 3: 2454-7379.

13. Heflin JA, Ford S, Stevens P (2016) Guided growth for tibia vara (Blount's disease). Medicine (Baltimore) 95: e4951.

14. Kulkarni RM, Rushnaiwala FMI, Kulkarni GS, Negandhi R, Kulkarni MG, et al. (2015) Correction of coronal plane deformities around the knee using a tension band plate in children younger than 10 years. Indian J Orthop 49: 208-218.

15. Ashby E, Eastwood D (2015) Characterization of knee alignment in children with mucopolysaccharidosis types I and II and outcome of treatment with guided growth. J Child Orthop 9: 227-233.

16. Das S, Ganesh GS, Pradhan S, Mohanty RN (2014) Outcome of eight-plate hemiepiphysiodesis on genu valgum and height correction in bilateral fibular hemimelia. J Pediatr Orthop B 23: 67-72.

17. Boero S, Michelis MB, Riganti S (2011) Use of the eight-plate for angular correction of knee deformities due to idiopathic and pathologic physis: Initiating treatment according to etiology. J Child Orthop 5: 209-216.

18. Ballal MS, Bruce CE, Nayagam S (2010) Correcting genu varum and genu valgum in children by guided growth: Temporary Hemiepiphysiodesis using Tension Band Plates. J Bone Jt Surg 92: $273-276$
19. Colmenares-Bonilla D, Vasconcelos-Martinez $M$, Guerra-Jasso J (2017) Be the best option for knee valgus deformity in adolescent patients with Morquio-A. Musculoskelet Surg 101:113-118.

20. Hosseinzadeh P, Ross DR, Walker JL, Talwalkar VR, Iwinski HJ, et al. (2016) Three methods of guided growth for pediatric lower extremity angular deformity correction. lowa Orthop J 36: 123-127.

21. Kumar A, Gaba S, Sud A, Mandlecha P, Goel L, et al. (2016) Comparative study between staples and eight plate in the management of coronal plane deformities of the knee in skeletally immature children. J Child Orthop 10: 429-437.

22. Gottliebsen M, Rahbek O, Hvid I, Davidsen M, Hellfritzsch MB, et al. (2013) Hemiepiphysiodesis: Similar treatment time for tension- band plating and for stapling: A randomized clinical trial on guided growth for idiopathic genu valgum. Acta Orthop 84: 202-206.

23. Lin TY, Kao HK, Li WC, Yang WE, Chang CH (2013) Guided growth by a stainless-steel tubular plate. J Pediatr Orthop 22: 306-310.

24. Fillingham YA, Luthringer T, Erickson BJ, Kogan M (2015) Does physical therapy prevent post-operative delay in return of function following tension-band plating? J Child Orthop 9: 483-487.

25. Leveille LA, Razi O, Johnston CE (2017) Rebound deformity after growth modulation in patients with coronal plane angular deformities about the knee: Who gets it and how much? J Pediatr Orthop 98: 37.

26. Kang S, Kim JY, Park SS (2016) Prediction of rebound phenomenon after removal of hemiepiphyseal staples in patients with idiopathic genu valgum deformity. Bone Jt J 98:1270-1275.

27. Burghardt RD, Specht SC, Herzenberg JE (2010) Mechanical failures of eight-plate guided growth system for temporary hemiepiphysiodesis. J Pediatr Orthop 30: 594-597.

28. Bachmann M, Rutz E, Brunner R, Gaston MS, Hirschmann MT, et al. (2014) Temporary hemiepiphysiodesis of the distal medial femur: MPFL in danger. Arch Orthop Trauma Surg 134:1059-1064.

29. Gyr BM, Colmer HG, Morel MM, Ferski GJ (2013) Hemiepiphysiodesis for correction of angular deformity in pediatric amputees. J Pediatr Orthop 33: 737-742.

30. Marangoz S, Buyukdogan K, Karahan S (2017) Is there a correlation between the change in the interscrew angle of the eight-plate and the delta joint orientation angles? Acta Orthop Traumatol Turc 51: 39-43.

31. Ceroni D, Dhouib A, Merlini L, Kampouroglou G (2017) Modification of the alignment between the tibial tubercle and the trochlear groove induced by temporary hemiepiphysiodesis for lower extremity angular deformities: A trigonometric analysis. J Pediatr Orthop 26: 204-210.

32. Masquijo JJ, Lanfranchi L, Torres-Gomez A, Allende V (2015) Guided growth with the tension band plate construct: $A$ prospective comparison of 2 methods of implant placement. J Pediatr Orthop 35: 20-25. 